\title{
écelu\&RatizidLS
}

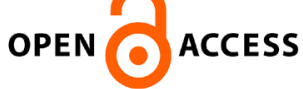

\section{BIOENGINEERED TOOTH EMULATION SYSTEMS FOR REGENERATIVE AND PHARMACOLOGICAL PURPOSES}

\author{
P. Pagella ${ }^{1, \$}$, A. Cordiale ${ }^{2, \$}$, G.D. Marconi ${ }^{1,3}$, O. Trubiani ${ }^{3}$, M. Rasponi ${ }^{2}$ and T.A. Mitsiadis ${ }^{1, *}$ \\ ${ }^{1}$ Orofacial Development and Regeneration, Institute of Oral Biology, University of Zurich, \\ 8032 Zurich, Switzerland \\ ${ }^{2}$ Department of Electronics, Information and Bioengineering, Politecnico di Milano, 20133 Milano, Italy \\ ${ }^{3}$ Department of Medical, Oral and Biotechnological Sciences, University "G. d'Annunzio" Chieti-Pescara, \\ 66100 Chieti, Italy \\ $\S$ These authors contributed equally to this work
}

\begin{abstract}
Genetic conditions, traumatic injuries, carious lesions and periodontal diseases are all responsible for dental pathologies. The current clinical approaches are based on the substitution of damaged dental tissues with inert materials, which, however, do not ensure full physiological recovery of the teeth. Different populations of dental mesenchymal stem cells have been isolated from dental tissues and several attempts have already been made at using these stem cells for the regeneration of human dental tissues. Despite encouraging progresses, dental regenerative therapies are very far from any clinical applications. This is tightly connected with the absence of proper platforms that would model and faithfully mimic human dental tissues in their complexity. Therefore, in the last decades, many efforts have been dedicated for the development of innovative systems capable of emulating human tooth physiology in vitro. This review focuses on the use of in vitro culture systems, such as bioreactors and "organ-on-a-chip" microfluidic devices, for the modelling of human dental tissues and their potential use for dental regeneration and drug testing.
\end{abstract}

Keywords: Tooth, dental pulp stem cells, periodontal ligament stem cells, bioreactors, microfluidics, organon-a-chip, stem cells, drug discovery, regeneration.

Address for correspondence: Thimios Mitsiadis, Institute of Oral Biology, University of Zurich, Plattenstrasse 11, 8032 Zurich, Switzerland.

Telephone number: +41 446343390 Email: thimios.mitsiadis@zzm.uzh.ch

Copyright policy: This article is distributed in accordance with Creative Commons Attribution Licence (http://creativecommons.org/licenses/by-sa/4.0/).

\section{Introduction}

Tooth pathologies affect the totality of the population, with a significant burden for global healthcare systems. Genetic conditions, traumatic injuries, caries and periodontal diseases can lead to tooth pathology and loss (Caton et al., 2011; Pagella et al., 2015). Clinical approaches consist mostly in the substitution of the damaged dental tissues with specific materials, resulting however in the loss of the vital components of the teeth and in a significant impairment of their functionality (Orsini et al., 2018a). Devitalised teeth show many undesirable characteristics, including strength reduction, increased fragility and predisposition to postoperative fracture (Adell et al., 1990; Caton et al., 2011; Esposito and Worthington, 2013; Fron Chabouis et al., 2013; Pagella et al., 2015). In case of tooth loss, implants are commonly used. While widely employed, implants are prone to infections and do not ensure the physiological functions of teeth (Callan, 2007; Caton et al., 2011; Orsini et al., 2018a; Pagella et al., 2015). To respond to these great unmet clinical needs, increasing attention was dedicated in the last years to the development of culture systems that emulate the physiology of human dental tissues and allows the study of their response to environmental and pharmacological stimuli as well as the generation of fully functional dental tissues.

\section{Tooth anatomy, development and pathology}

Teeth are composed of a unique combination of hard and soft tissues (Nanci, 2013; Pagella et al., 2020c). The enamel is the hardest tissue of the human body and covers the crown of the tooth. The enamel is supported by the dentine, a second highly mineralised tissue. The central portion of the tooth is occupied by 
the dental pulp, a connective tissue that conveys innervation and vascularisation. Nerve fibres from the trigeminal ganglion enter the dental pulp from the apical foramen and extend until within the dentine, conducting pain and sensitivity. The dental pulp is supported by a rich vascularisation, which guarantees trophic support and tooth survival and regeneration. The tooth is anchored to the surrounding alveolar bone through the periodontium, which absorbs the various shocks associated with mastication and provides tooth stability by continuously remodelling its extracellular matrix, the periodontal ligament (Fig. 1a) (Nanci, 2013; Pagella et al., 2020c). Similarly to the dental pulp, the periodontal ligament is supported by a rich vascular plexus and a rich neuronal network.

The development of the tooth results from sequential and reciprocal interactions between cells of the oral epithelium and the cranial neuralcrest-derived mesenchyme (Kollar, 1986). Oral epithelial cells generate ameloblasts that produce the enamel and then drive the development of the dental roots (Diekwisch, 2001; Mitsiadis and Graf, 2009; Nanci, 2013). Dental mesenchymal cells generate odontoblasts, the cells responsible for dentine production, as well as the dental pulp and the periodontium (Mitsiadis and Graf, 2009; Nanci,
2013). In pathological conditions, such as mild carious lesions, odontoblast activity is stimulated to elaborate a reactionary dentine (Smith et al., 1995). Dental traumas involving violent stresses (i.e. cavity preparations) lead to odontoblast death and newly formed odontoblast-like cells generate reparative dentine (Fig. 1b) (Goldberg et al., 2011). In case of an extensive injury or infection, the reparative and regenerative responses of the dental pulp are not sufficient and the dental pulp undergoes necrosis (Orsini et al., 2018b). The periodontium is continuously exposed to mechanical, chemical and bacterial insults. Periodontal injuries and infections are often not compensated by sufficient regenerative responses and, thus, represent the most frequent cause of tooth loss (Papapanou, 1996).

Both the dental pulp and the periodontium contain mesenchymal stem cells (MSCs), named dental pulp stem cells (DPSCs) and periodontal stem cells (PDLSCs), respectively (Fig. 1a) (Gronthos et al., 2000; Roguljic et al., 2013). DPSCs and PDSCs are multipotent and respond to cellular, chemical and physical stimuli to ensure homeostasis and regeneration of dental tissues. In the last decades, isolated DPSCs and PDSCs have been the subject of intense investigation as possible tools for the
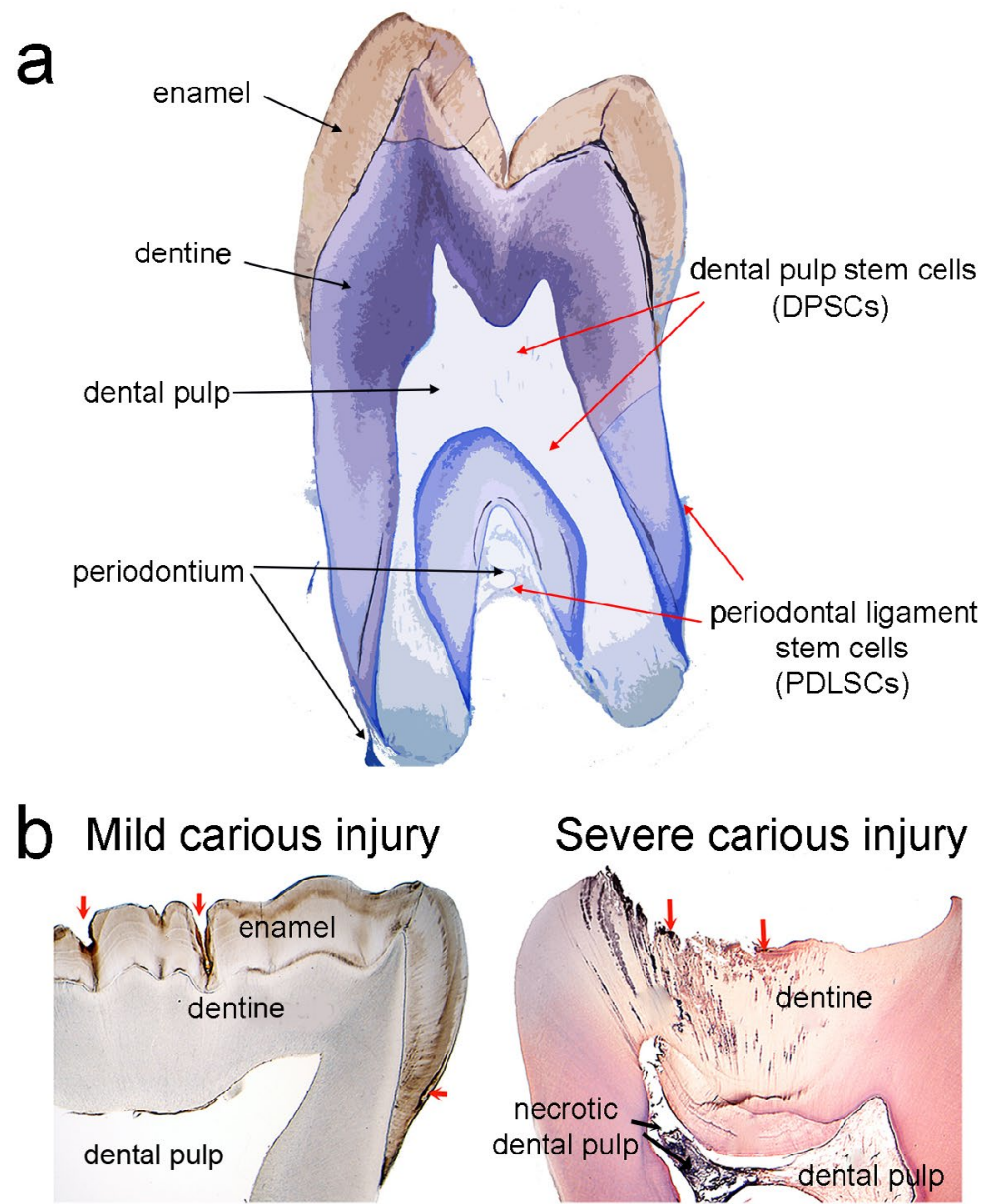

Fig. 1. Tooth anatomy and histology in physiological and pathological conditions. (a) Schematic representation of a human premolar. (b) Histological sections of human carious teeth. Left: ground section, unstained, showing mild carious injuries (red arrows) affecting only enamel. Right: decalcified section, haematoxylin and eosin, showing a severe carious injury (red arrows) with bacterial invasion (asterisks: bacterial front within dentine). Adapted from Orsini et al. (2018b). 
regeneration of both dental and non-dental tissues (Orsini et al., 2018a). In vivo studies aiming at the regeneration of dental pulp and periodontium are promising but they have not managed yet to recreate fully functional tissues (Chen et al., 2020; Xu et al., 2019; Xuan et al., 2018). This can be attributed to the limited information that is currently available on the function and properties of human MSCs in dental pulp and periodontium in vivo and their interaction with their microenvironment. Stem cell behaviour is indeed regulated by molecular cues produced in their microenvironment (also called the stem cell niche) by stromal cells, neurons, vascular-related cells and immune cells as well as by physical factors such as shear stress, stiffness and topography (Lane et al., 2014; Pagella et al., 2021). Despite their biological and clinical relevance and although the very recent publication of the single-cell atlas of human teeth (Pagella et al., 2021), a thorough understanding of the interactions between dental stem cells and their microenvironment is still lacking. This is tightly connected with the absence of proper platforms that would model human dental tissues in all their complexity.

\section{Platforms for studying human dental tissues in vitro}

Many studies have been performed in classical bidimensional (2D) culture systems and these have been pivotal to characterise the basic properties of the various dental stem cell populations (Mitsiadis et al., 2015). However, the translation of these results to the clinical practice has been very limited, highlighting the need for more accurate emulation systems (Skardal et al., 2016). Indeed, these 2D culture systems lack most of the features that characterise dental tissues in vivo, such as interactions between the cells and the extracellular environment as well as with other cell types (Pampaloni et al., 2007). Three-dimensional (3D) culture systems have been developed to overcome some of these limitations. 3D structures such as spheroids and organoids allow complex cell-cell interactions, creation of gradients of oxygen, circulation of nutrients and soluble signals, which lead to the generation of tissue-specific heterogeneous cell types (Yin et al., 2016). Spheroids have been generated from both dental epithelial and mesenchymal stem cells (Berahim et al., 2011; Natsiou et al., 2017; Stevens et al., 2008) and have displayed the expression of tissue-specific differentiation gradients when compared to 2D culture systems (Berahim et al., 2011). 2D and 3D culture systems have been most recently complemented by increasingly more complex systems that allow for the study of dental stem cells in the presence of the other cell types that compose their niches as well as their responses to physical and chemical stimuli. The following sections focus on the use of these systems, including bioreactors and microfluidic "organ-on-a-chip" devices, for the emulation and regeneration of human dental tissues and the study of their response to pharmacological treatments (Table 1, 2).

\section{Various models of dental tissue-specific bioreactors}

Bioreactors have been adopted as a strategy to create more accurate and complex biological models that better mimic pathophysiological conditions, to recreate brand new dental tissues or test novel pharmaceutical products. Such devices are meant to overcome static culture limitations, enhance oxygenation and nourishment of the constructs

\section{Perfusion and shear stress bioreactors}

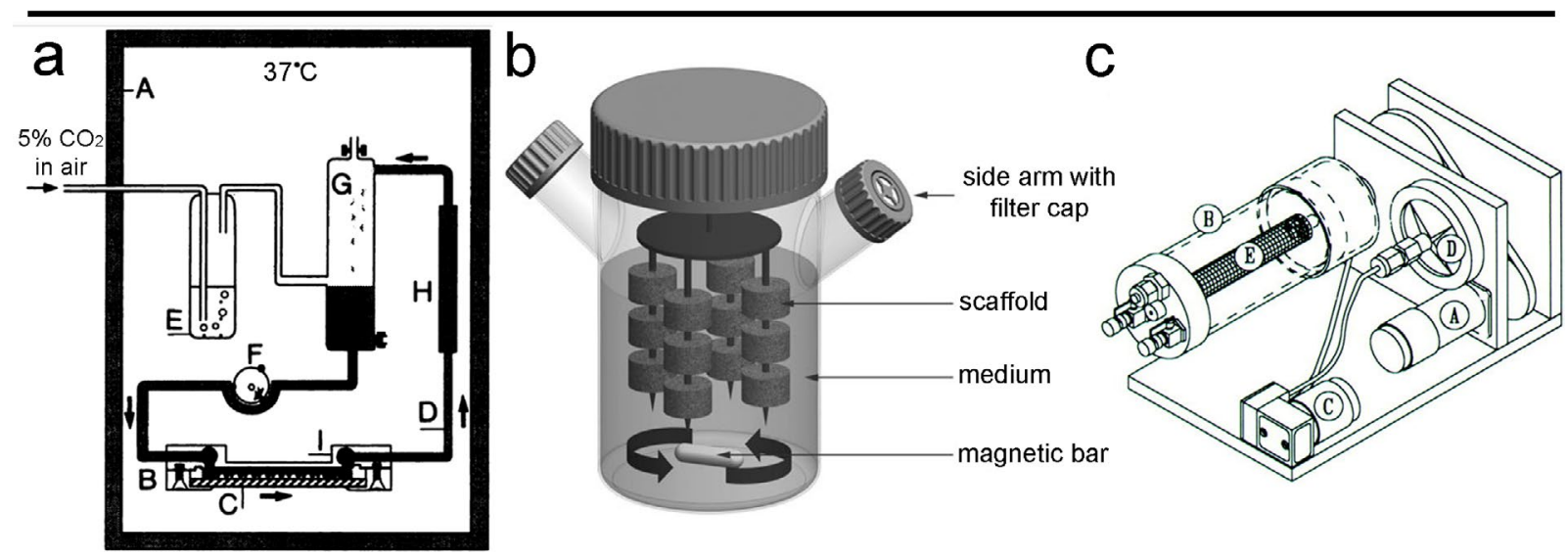

Fig. 2. Overview of perfusion and shear stress bioreactors used for the study and emulation of human dental tissues. (a) Adapted from Kraft et al. (2010). (A) Incubator; (B) parallel plate flow chamber; (C) glass slide with cell monolayer; (D) fluid culture medium; (E) $\mathrm{H}_{2} 0 ;(\mathbf{F})$ revolving pump; (G) gas phase of $5 \% \mathrm{CO}_{2}$ in air; $(\mathbf{H})$ flow probe; (I) polycarbonate plate with two slits through which medium enters and exits the channel. (b) Adapted from Woloszyk et al. (2014). (c) Adapted from Hammond and Hammond (2001). (A) A $24 \mathrm{~V}$ direct-current motor drives a belt that rotates the (B) cylindrical culture vessel along its horizontal axis. (C) An air pump draws incubator air through a (D) $0.22 \mu \mathrm{m}$ filter and discharges it through a rotating coupling on the shaft that carriers the vessel. (E) The oxygenator is wrapped around the centre post. 
and, depending on their design, they are able to provide different ranges and frequencies of mechanical stimulation (Wendt et al., 2009). Physical conditioning parameters are chosen according to the cues experienced by the tissues in homeostasis, developmental and pathological stages. Dynamic culture systems are in particular crucial for tissue engineering advancements and their translation to clinical studies.

\section{Perfusion and shear stress bioreactors}

Perfusion of the constructs enhances transport of oxygen and nutrients that thus are able to reach the inner parts of the scaffold. At the same time, perfusion can be used to induced shear stress applied to the cells. One of the first studies involving this type of stimulation for dental application adopted a parallel-plate chamber and a fluidic circuit to convey a pulsatile flow to a DPSC monolayer (Kraft et al., 2010). Such system consisted of a polycarbonate plate culture chamber where medium flow is driven by a peristaltic pump drawing from an air-filtered reservoir (Fig. 2a). This configuration enables to finely tune the shear stress applied to the cells by varying the fluid flowrate. Furthermore, the roller pump is responsible for the pulsatile motion. The drawbacks are related to the $2 \mathrm{D}$ culture limited ability to produce functional tissues for regeneration or complex models. It is possible to include a scaffold in the chamber by changing its design and assembling procedures. In this instance, in case of direct perfusion, finding a proper flowrate threshold is mandatory since the medium is forced to flow through the scaffold pores and high values of shear stress could impair cell adhesion and viability. Perfusion and shear stress can also be conveyed by means of batch systems such as Spinner Flask bioreactors or Rotating Wall Vessel bioreactors (RWV), which are the most versatile in terms of cell types and scaffold to be employed. Spinner Flask devices are simple and easy to use: a large chamber is filled with culture medium and seeded scaffolds are placed on specific holders. Air

\section{Hydrostatic pressure and compression bioreactors}
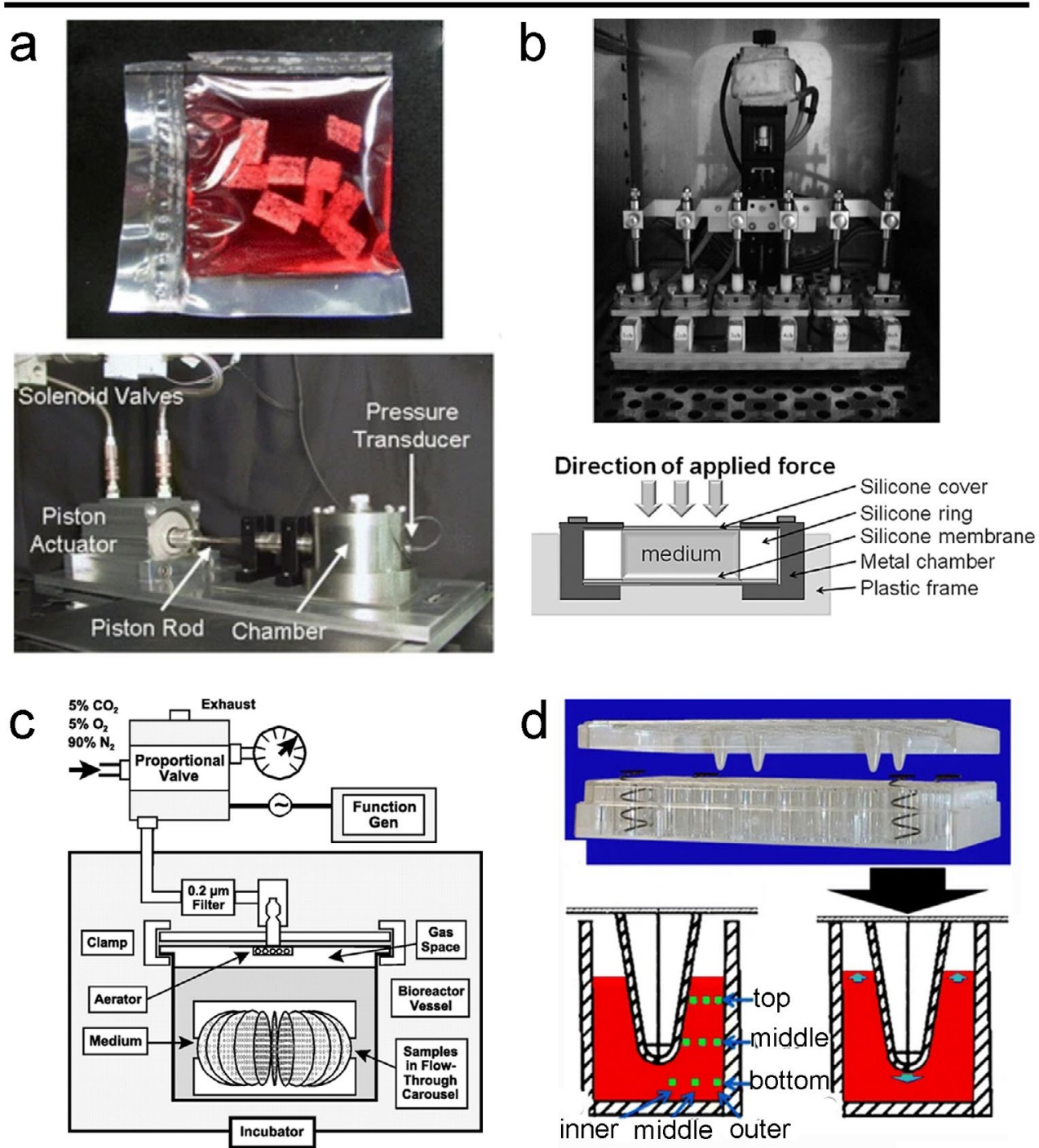

Fig. 3. Overview of hydrostatic pressure and compression bioreactors used for the study and emulation of human dental tissues. (a) Adapted from Reza and Nicoll (2008). (b) Adapted from Miyashita et al. (2017). (c) Adapted from Wenger et al. (2011). (d) Adapted from Ji et al. (2014). 
filters are used to guarantee both oxygenation and sterility, while medium motion and shear stress on the surface of the constructs are provided by stirring bars (Fig. 2b). This dynamic culture method has already been adopted with human DPSCs (hDPSCs) seeded on silk fibroin scaffolds to investigate their differentiation behaviour (Woloszyk et al., 2014). As for the RWV system, it has been previously used to culture enamel organ epithelium cells on dextran microbeads (Li et al., 2012a). It consists of a cylindrical vessel and an internal coaxial oxygenator while cells are seeded on microcarriers or scaffolds (either free to move or placed on holders). The motion of the medium is provided by slow rotation of the vessel and the modulus of the stimulation is related to the revolutions per minute (Fig. 2c). In general terms, batch bioreactors employ large amount of culture medium and costs of reagents must be considered if expensive chemicals, such as growth factors, are needed. Furthermore, mass transport towards the bulk of the seeded material is limited, particularly after long culture periods because cells proliferation and extracellular matrix (ECM) production on the surface prevent deeper cells from receiving nutrients. Cross contamination between samples cannot be avoided with such methods and control of the stimulation is also limited, except for the RWV system whose rotation causes laminar flow and nearly homogenous shear fields. Other disadvantages are related to the need to manually replace exhausted medium and to the bumping between carriers or scaffold and the walls that can impair cells functionality. A custommade apparatus has been previously used to provide titanium implants with tissue engineered periodontal ligament (PDL) (Gault et al., 2010). Briefly, PDL cells cushions were cultured on hydroxyapatite (HAP)coated titanium pins, incubated in vessels and tested for bone integration after implantation. In this case, perfusion of the cellular cushion was obtained via the medium flow occurring through the small gap between the pin and the walls of the vessel.

Hydrostatic pressure and compression bioreactors Hydrostatic pressure is crucial for all tissues that transduce forces, such as those filled with fluids or highly hydrated, as their loading results in

\section{Strain and combined bioreactors}
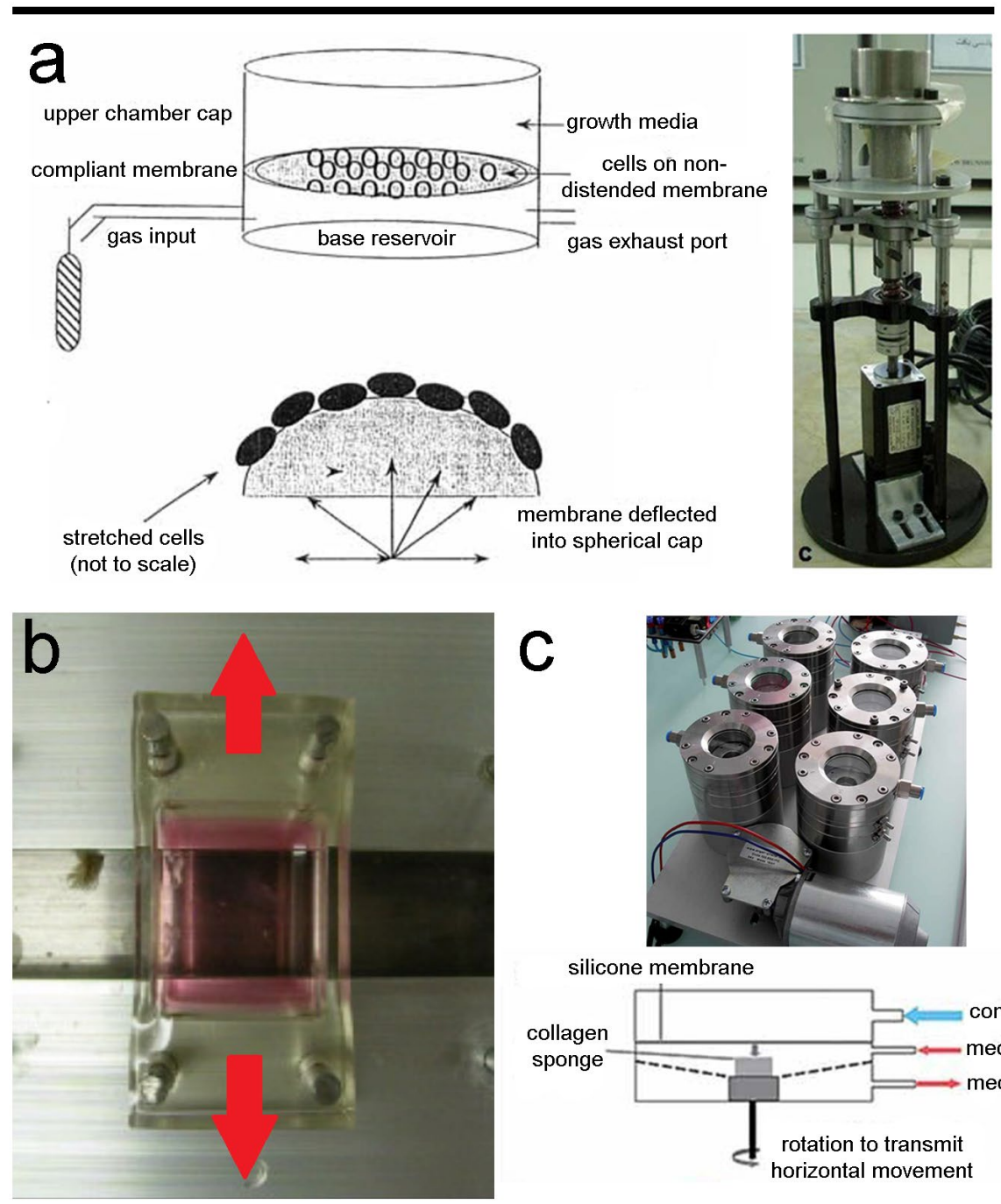

silicone membrane

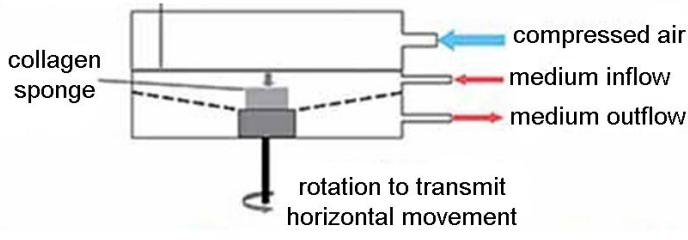

Fig. 4. Overview of strain and combined bioreactors. (a) Adapted from Howard et al. (1998). (b) Adapted from Hata et al. (2013). (c) Adapted from Mathes et al. (2010). 
interstitial pressure modification (Reinwald and El Haj, 2018). A typical hydrostatic pressure bioreactor includes a chamber and a piston, which regulates its pressure. The chamber contains scaffolds and medium while pressure is conveyed equally to all surfaces in contact with the liquid phase. A similar system has been used with hDPSCs cultured on glass substrates: seeded glass coverslips were put in a plastic bag filled with medium and placed in a pressure chamber containing water (Fig. 3a). This "sack technique" guarantees sterility and allows the bioreactor chamber to be instantly reusable without the need for complex assembling procedures ( $\mathrm{Yu}$ et al., 2009). A more sophisticated apparatus was designed to culture hDPSCs adhered to micropatterned membranes and stimulate them with cyclic pressure strain (Fig. 3b). More specifically, the system comprised six metal chambers, each housing a sample of seeded membrane on the bottom. Silicone rings and covers ensured watertightness and sterility while pressure was applied through external pistons- actuator elements that pushed on deformable silicone covers. This pressure was hydraulically conveyed to cells thanks to the medium. This bioreactor is characterised by great versatility and the presence of multiple chambers enables to use independent samples without the risk of cross contamination, while facilitating the investigation of biological events at different time points (Miyashita et al., 2017). In another study, a high throughput system hydrostatic pressure was designed by hosting previously seeded coverslips in a polycarbonate "carousel" holder with 18 radial slots (Wenger et al., 2011). The holder was placed in a vessel containing medium and a controlled amount of gas (Fig. 3c). By changing the amount of gas, different magnitudes of pressure can be applied cyclically, while the composition of the gaseous phase enables to have custom concentrations of oxygen and carbon dioxide regardless of the concentrations inside the incubator. The filtered injection of gases is performed by a pumping system placed outside of the incubator due to its hindrance.
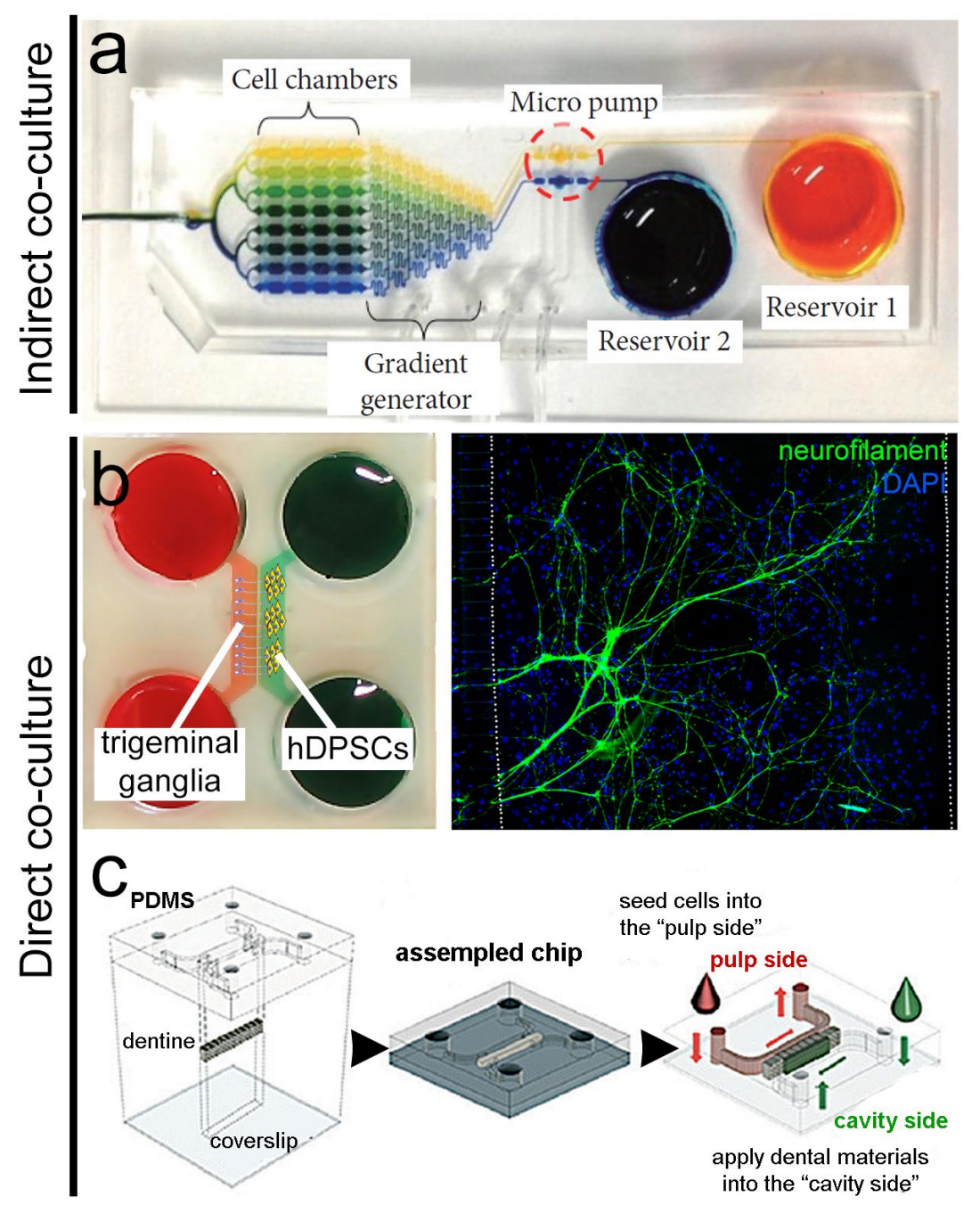

Fig. 5. Overview of microfluidic devices used for the study of human dental tissues. (a) Microfluidic device for the study of the effects of different concentrations of factors secreted by human gingival fibroblasts and human periodontal ligament stem cells on human dental pulp populations. Adapted from Kang et al. (2016). (b) Microfluidic device used for the co-culture of trigeminal ganglia or neurons and hDPSCs. Adapted from Pagella et al. (2020b). (c) Microfluidic device used for the co-culture of hDPSCs and dentine fragments. Adapted from Franca et al. (2020). 


\begin{tabular}{|c|c|c|c|c|c|c|c|c|c|c|c|c|}
\hline 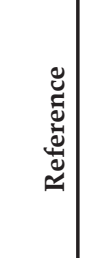 & 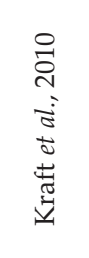 & 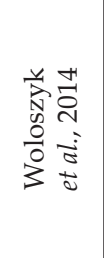 & 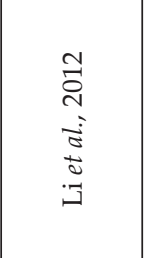 & 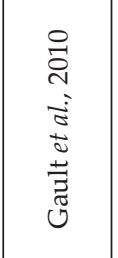 & 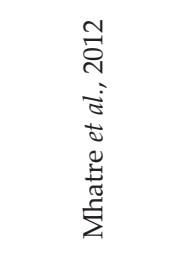 & 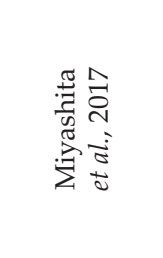 & 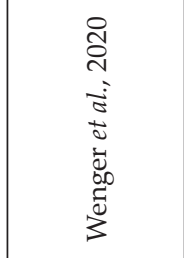 & 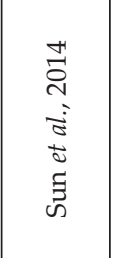 & 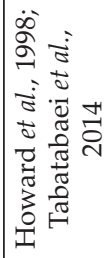 & 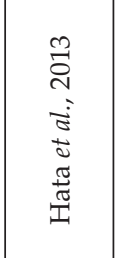 & 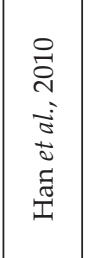 & 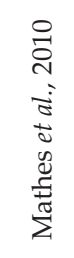 \\
\hline 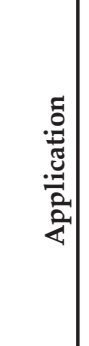 & 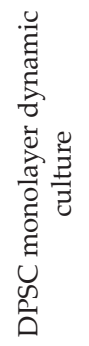 & 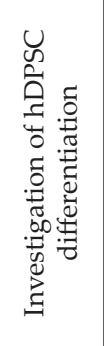 & 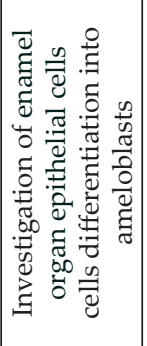 & 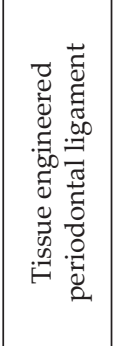 & 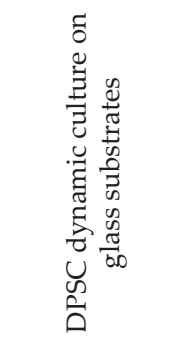 & 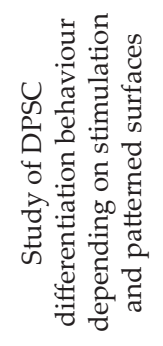 & 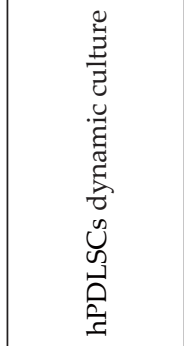 & 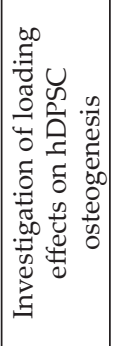 & 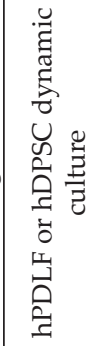 & 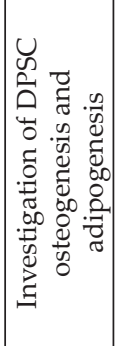 & 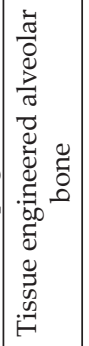 & 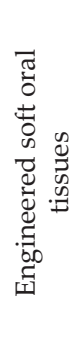 \\
\hline 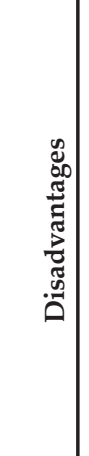 & 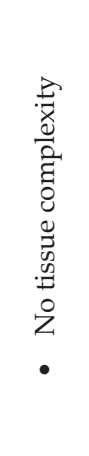 & 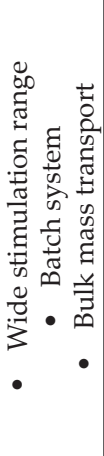 & 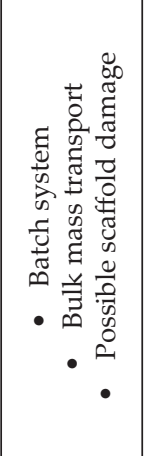 & 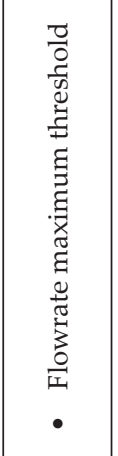 & 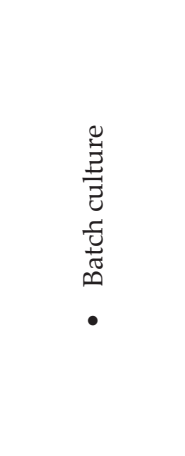 & 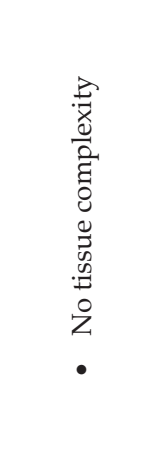 & 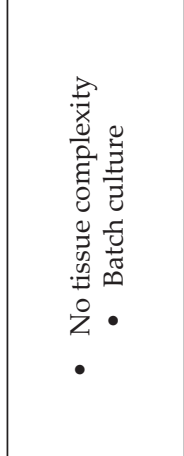 & 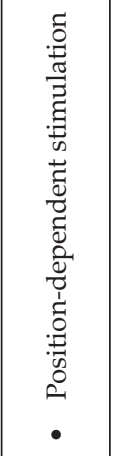 & 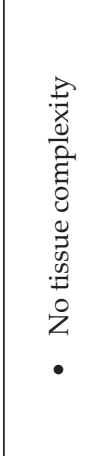 & 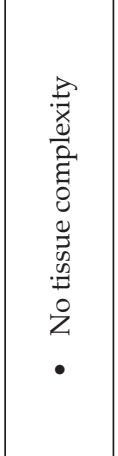 & 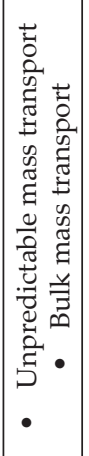 & 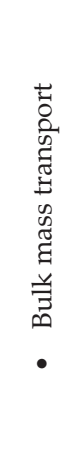 \\
\hline 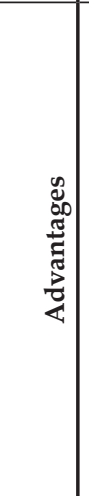 & 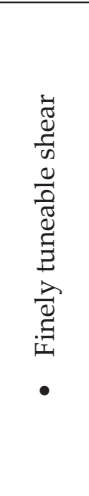 & 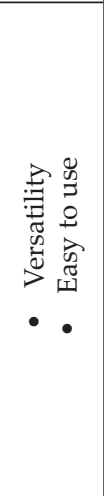 & 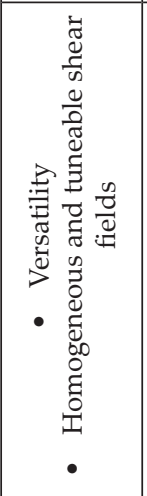 & 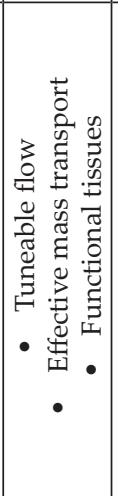 & 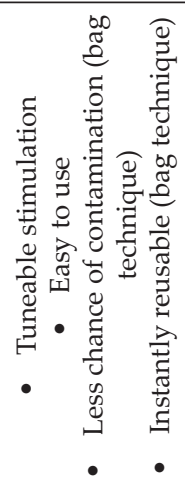 & 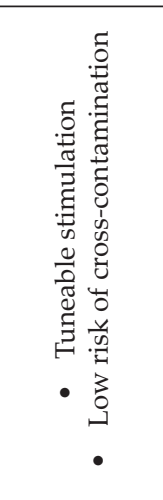 & 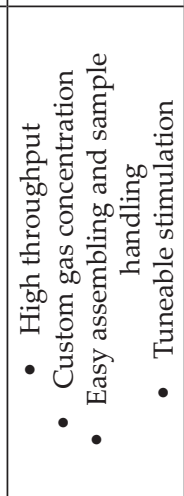 & 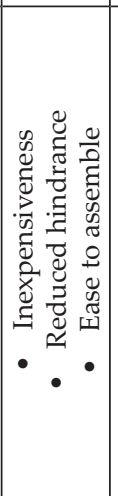 & 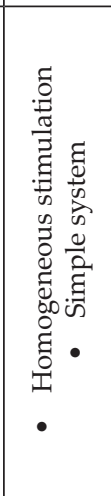 & 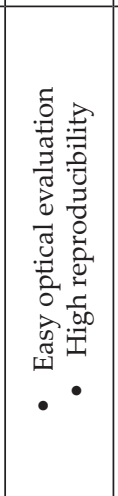 & 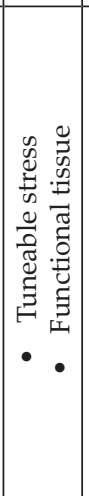 & 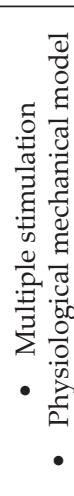 \\
\hline 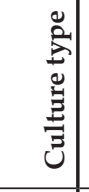 & خे & लि & तิ & तิ & حิ & $\vec{\sim}$ & ते & ले & จิ & حิ & लि & ले \\
\hline 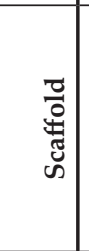 & $\begin{array}{l}: 0 \\
\overline{0} \\
0 \\
0 \\
0 \\
0 \\
0 \\
0 \\
0 \\
0\end{array}$ & 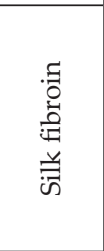 & 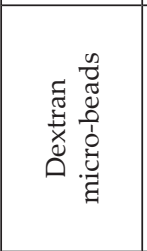 & 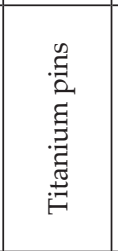 & 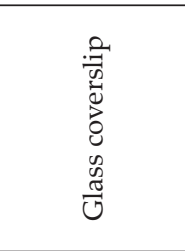 & 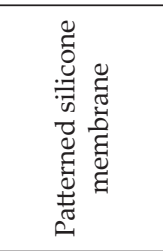 & 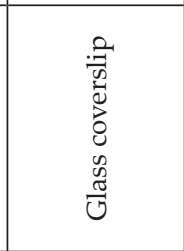 & $\begin{array}{l}\vec{D} \\
\infty \\
0 \\
0 \\
0 \\
0 \\
0 \\
0\end{array}$ & 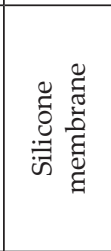 & 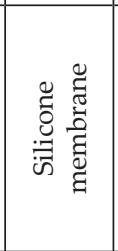 & 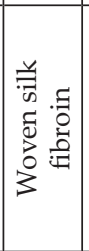 & 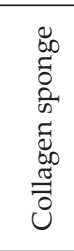 \\
\hline 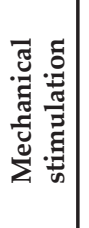 & 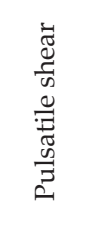 & $\begin{array}{l}\text { むँ } \\
\text { ๘ }\end{array}$ & 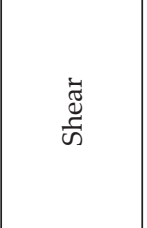 & $\begin{array}{l}\tilde{\varpi} \\
\tilde{w}\end{array}$ & 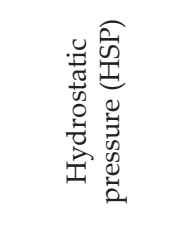 & 馬 & 馬 & 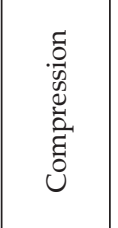 & 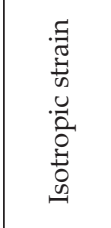 & 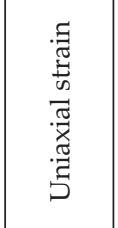 & 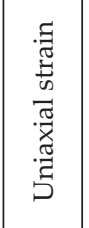 & 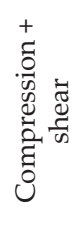 \\
\hline 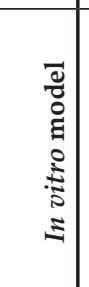 & 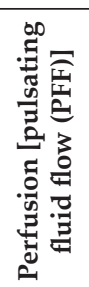 & 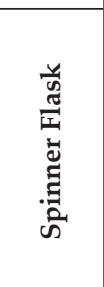 & 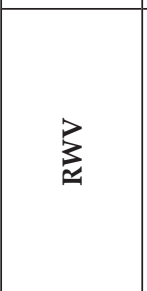 & 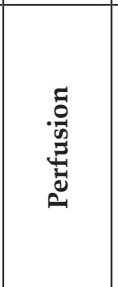 & 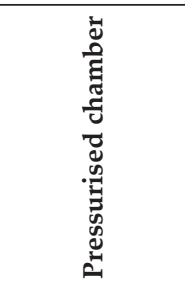 & 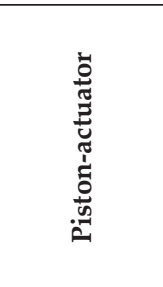 & 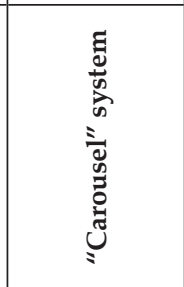 & 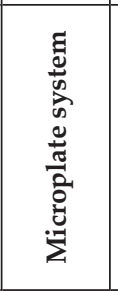 & 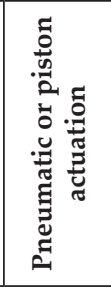 & 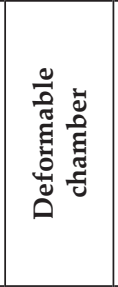 & 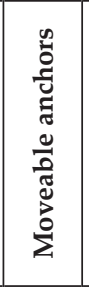 & 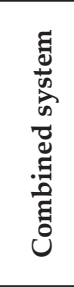 \\
\hline
\end{tabular}


Table 2. Microfluidic culture systems used for dental tissues engineering.

\begin{tabular}{|c|c|c|c|}
\hline In vitro model & Features & Application & References \\
\hline $\begin{array}{c}\text { Indirect } \\
\text { culture system }\end{array}$ & $\begin{array}{c}\text { High throughput } \\
\text { Versatility } \\
\text { Low sample consumption }\end{array}$ & $\begin{array}{c}\text { Investigation of hGF hPDLSCs } \\
\text { secreted factor influence on (stem } \\
\text { cells from human exfoliated } \\
\text { deciduous teeth (SHED) } \\
\text { population }\end{array}$ & $\begin{array}{c}\text { Kang } \text { et al., } \\
2016\end{array}$ \\
\hline $\begin{array}{c}\text { Direct culture } \\
\text { system }\end{array}$ & $\begin{array}{c}\text { Physiological microenvironment model } \\
\text { Versatility }\end{array}$ & $\begin{array}{c}\text { Tooth innervation studies during } \\
\text { developmental stages }\end{array}$ & $\begin{array}{c}\text { Pagella } \text { et al., } \\
\text { 2014; 2020a; } \\
2020 \mathrm{~b}\end{array}$ \\
\hline $\begin{array}{c}\text { Dentine-resin } \\
\text { interface }\end{array}$ & $\begin{array}{c}\text { Physiological microenvironment model } \\
\text { Dentine fragment } \\
\text { Live imaging }\end{array}$ & $\begin{array}{c}\text { Model of stem cells from the } \\
\text { apical papilla (SCAP)-derived } \\
\text { odontoblast and restorative resin } \\
\text { interaction }\end{array}$ & $\begin{array}{c}\text { Franca et al., } \\
2020\end{array}$ \\
\hline
\end{tabular}

Another advantage of such design is the large number of samples stimulated at the same time and the easy assembling procedure (Wenger et al., 2011).

Compression stimulus is another valid choice for load-bearing tissues and it is conveyed by directly deforming the seeded surface or scaffold. The alveolar bone is continuously loaded during chewing movement; hence, proper magnitudes of compression are considered to favour differentiation toward osteogenesis. A bioreactor was designed to mimic forces applied to alveolar bone cells during chewing motion (Ji et al., 2014). Such bioreactor can be assembled starting from common lab equipment. Four wells of a microplate constitute the culture chambers containing a cell-laden agarose gel. Pressure is exerted on each of them by the bottom part of Eppendorf tubes adhered to the microplate lid. Tubes are glued to the lid so that they are coaxially aligned to the culture chambers. The lid is pressed cyclically by an actuator and the compression is transferred to the gels through the reaction tubes. Springs are included so that the lid can return to its original position after the compression (Fig. 3d) (Ji et al., 2014). While this system is a simple, compact and inexpensive way to convey compression to $3 \mathrm{D}$ cultures, each cell does not experience the same stimulation, which depends on their position inside the chamber. In fact, since the gel is not confined, cells undergo compression or stretch when they are in the lower or the upper part of the well, respectively.

\section{Strain bioreactors}

Tensional forces have also been investigated as physical conditioning cues both for 2D and 3D cultures. Typical stretching systems rely on seeded elastomeric membranes that are deformed in an isotropic fashion or following a preferential direction. Possible methods to induce deformation consist of a pneumatic circuit that inflates an air chamber below the culture (Howard et al., 1998) or of a pistonactuator element that pushes on the compliant substrate (Tabatabaei et al., 2014) (Fig. 4a). A method to exert uniaxial tension was developed by using a silicone chamber hosting a 2D culture paired with an actuator that cyclically pulls the corners towards opposite directions (Fig. 4b) (Hata et al., 2013). Using silicone as a building material allows for easy optical evaluation of the samples without compromising their sterility or interrupting the ongoing culture. This system, even though still limited to 2D cultures, ensures high reproducibility because almost every cell is subjected to similar stimulation (Hata et al., 2013). In case of a 3D culture, the most adopted design choice consists in gripping two sides of the construct with a fixed anchor and a moveable holder so that the motion of the latter induces the stretching of the engineered tissue. These components of the bioreactors are immersed in a chamber containing medium and need an external actuation that induces their motion. Such design has been used to culture hDPSCs on silk fibroin scaffolds for alveolar bone regeneration purposes (Han et al., 2010).

\section{Combined stimulation bioreactors}

Depending on the tissue to model or regenerate in vitro, multiple physical cues can be applied simultaneously by means of more sophisticated bioreactors. One example was employed by Mathes et al. (2010) to mimic the mechanical environment of soft oral tissues. This system combines compression and shear forces and comprises six stainless steel chambers continuously streamed with medium. Collagen sponge scaffolds are held on the bottom of each chamber by swaying holders and a compliant silicone membrane exerts compression when it is pneumatically deformed (Fig. 4c). It should be noted that several experimental factors contribute to the outcome: chemical factors, environmental conditions, cell populations, scaffolds chemical and mechanical properties, viscoelasticity and microstructure of the biomaterial, surface topography. Hence, comparing specific results of different studies remains challenging. Moreover, cellular behaviour strictly depends on the parameters that define mechanical stimulation such as frequency, magnitude and duration. All these aspects shall be kept in 
consideration when interpreting results obtained from bioreactors.

\section{Microfluidic “organ-on-a-chip" devices}

Considerable advances in microfluidics and microfabrication techniques during the last decades resulted in the development of devices able to handle and analyse fluids at the microscale, also termed "lab-on-a-chip" systems. These devices rely on miniaturised circuits that can be provided with reservoirs, pumps and valves. Their main advantages are the reduction of samples and reagents volumes, the high throughput, controlled transport phenomena and portability. Lab-on-a-chip systems can perform basic and complex laboratory operations and assays starting from biological samples and have started to be used for diagnostic purposes. For example, microfluidic devices have been used to analyse saliva and detect both oral and systemic diseases (Salehipour Masooleh et al., 2020).

Organs-on-chips are microfluidic devices used for culturing living cells in continuously perfused, micro-engineered chambers that are increasingly exploited to model the physiological functions of organs and tissues (Bhatia and Ingber, 2014). The goal of these systems is to reproduce basic features of tissue or organ function, going beyond classic 2D monoculture systems. In the last years, the increasing complexity of microfluidic co-culture systems is allowing to more faithfully model real, in vivo-like situations (Maoz et al., 2018; Nikolaev et al., 2020). In these set-ups, two or more micro-channels are connected by porous membranes, lined by different cell types on the opposite sides, to recreate tissuetissue interfaces and to emulate as faithfully as possible the minimal functional units that would recapitulate tissue- and organ-level functions (Bhatia and Ingber, 2014; Huh et al., 2010). These devices are produced by soft lithography (Duffy et al., 1998) and composed predominantly of poly-dimethylsiloxane, a transparent polymer that is bonded on a thin glass plate so that real-time, high-resolution imaging of cultures cells and tissues is feasible (Bhatia and Ingber, 2014). These systems can be engineered to incorporate the several environmental cues that affect tissue and organ functions (Bhatia and Ingber, 2014; Griep et al., 2013; Smith and Gerecht, 2014) and permit analysis of organ-specific responses. These devices have already been used to model, among others, the liver (Sivaraman et al., 2005), kidney (Baudoin et al., 2007), intestine (Kim and Ingber, 2013), lung (Huh et al., 2012), heart (Grosberg et al., 2011), muscles (Grosberg et al., 2012), bone (Park et al., 2012), bone marrow (Torisawa et al., 2014), skin (Atac et al., 2013), blood vessels (Shin et al., 2004), nerves (Park et al., 2013; Shi et al., 2013) and brainblood barrier (Adriani et al., 2017). Organs-on-chips system are being increasingly employed to model tissue responses to mechanical stimuli and shear stress (Bhatia and Ingber, 2014), electrical activity (Douville et al., 2010), immune responses (Benam et al., 2016; Huh et al., 2010; Kim et al., 2016b), neuronal activity (Achyuta et al., 2013) and whole microbiomas (Kim et al., 2016a; Kim et al., 2016b) as well as for drug testing (Bhatia and Ingber, 2014), including pharmacokinetic and pharmacodynamics studies (Abaci and Shuler, 2015). Finally, the vascular channels of different organ-specific chips can be linked to study multi-organ physiological coupling (Maschmeyer et al., 2015). Chips can be engineered to faithfully reconstitute the microenvironment of the cell/tissue of interest. Fluid flow, cell and extracellular matrix patterning as well as mechanical forces can all be finely regulated and defined to reconstitute a physiological microenvironment that would mimic in vivo tissue organisation or, for example, stem cell niches. Similarly, these variables can be altered to assess the response of tissues and cells to specific stimuli in a complex, integrated environment.

\section{Microfluidic devices for the emulation of human dental tissues}

Only recently, these systems started to be applied to dental research. Simple microfluidic devices have been used to perform indirect co-cultures and test the influence of different concentrations of factors secreted by human gingival fibroblasts (hGF) and human periodontal ligament stem cells (hPDLSCs) on dental pulp cell populations (Kang et al., 2016). Briefly, the device has two reservoirs containing respectively conditioned medium and basic medium, which are connected to a gradient generator circuit that exploits laminar flow and diffusion to create different factors concentrations and convey each of them to separated culture chambers (Fig. 5a). The main advantage is the remarkable high-throughput and the possibility of testing different experimental conditions simultaneously (Kang et al., 2016).

For direct co-culture, chips with different features needed to be introduced. These chips often consist of reservoirs for medium and different parallel channels containing 2D cultures or cell-laden hydrogels. Depending on the lateral connection between channels, it is possible to control the interaction between cell populations. This type of chip was used to emulate tooth innervation in vitro. In vivo, mouse teeth actively repeal innervation during embryonic development, while they are rapidly innervated few days after birth, at the onset of the mineralisation of dental hard tissues (Pagella et al., 2014a). Co-cultures of trigeminal ganglia with embryonic and postnatal teeth in microfluidic chips faithfully reproduced the in vivo situation, for example innervation was constantly repealed over several days of culture by embryonic teeth, while it was promoted and attracted by postnatal teeth (Pagella et al., 2014b). Then, this chip was employed to study the neurotrophic properties of ameloblastomas (Pagella et al., 2020a) as well as to compare the neurotrophic properties of hDPSCs and human bone marrow stem cells, showing that 
hDPSCs induce the growth of significantly longer axons as well as the formation of extensive neuronal networks (Pagella et al., 2020b). In this case, narrow grooves between the channels allow only axons to pass and establish a connection between the compartments (Fig. 5b).

Biological material other than cells can be introduced in the microfluidic devices. França et al. (2020) attempted to create a model of tooth that could mimic the interface between dentine and restorative resins and monitor their interaction with stem-cellsderived odontoblasts in real time. The device has a simple design: it comprises two parallel channels with two chambers that are separated by a decellularised dentine fragment retrieved from a donor. Dentine is inserted in a central groove structure and has the aim to separate the pulp side of the chip, where cells are seeded, and the cavity side, where the biomaterial is inserted (Fig. 5c).

\section{Organ-on-a-chip as a novel frontier for drug discovery}

Organ-on-a-chip devices are also increasingly used for drug discovery. Drug discovery can be defined as a very complex process needed to identify novel molecules that have the potential to become therapeutic agents. The main goal of the drug discovery process is to recognise a novel molecule that may be useful to address unmet medical needs across different therapeutic fields. Discovery progression includes target identification and validation, hit identification, lead production and optimisation as well as detection of a promising molecule candidate for additional development. The development part includes optimisation of chemical synthesis and its formulation, toxicological studies in animals, clinical trials and ultimately regulatory approval (Mohs and Greig, 2017). Discovery and development processes are time-consuming and very expensive. Most of the time, the drug clinical trial failing may be linked to the lack of predictivity of current preclinical models. Recent studies have established that microfluidics tool have the ability to realise an interactive and dynamic cell microenvironment, extremely important to reproduce cell and organ architectures in vivo. For this reason, the microfluidic technology could be extremely useful to identify promising candidate molecule and to evaluate drug concentrations in a more representative and less consuming time (Polini et al., 2014). The combination of 3D cultures with microfluidic technology provides a more suitable culture environment and increase tissue or organ properties, offering a promising novel platform for in vivo-like tissue-based methods, such as organ-onchip systems (Li et al., 2012b).

\section{Microfluidic platforms for pharmacokinetic and pharmacodynamic modelling}

These advanced micro-engineered platforms not only simulate the physiological properties at the cellular or organ level, but also could be used to predict human pharmacokinetic and pharmacodynamic responses to drugs, avoiding the use of animal models (Prantil-Baun et al., 2018). During drug development, experiments on cells and animals are performed to assess pharmacokinetic and pharmacodynamic parameters, frequently with the support of mathematical pharmacokinetic and pharmacodynamic models. Microfluidic tools, due to their structure, which integrates several components, can be particularly important for reproducing drug pharmacokinetic, which play a key role in defining the in vivo pharmaceutical activity. During in vitro drug testing, microfluidic devices could allow for the evaluation of physiological dynamic drug concentration profiles and, thus, help to reproduce in vivo drug outcomes more faithfully, decreasing the use of animal models during drug progression. For example, proof-of-concept studies have assessed the capability of microfluidic pharmacokineticpharmacodynamic devices to evaluate the doseand time-dependent effects of doxorubicin and gemcitabine alone or in combination therapy. Such studies have demonstrated the ability of these microfluidic pharmacokinetic-pharmacodynamic devices to model dose- and time-dependent effects of these drugs on cell viability, as well as species-specific (human, mouse) pharmacokinetic profiles (Guerrero et al., 2020). Organ-on-a-chip devices have also been used to model multi-organ pharmacokineticpharmacodynamic relationships. In a recent study, a heart-on-a-chip model was fluidically linked to a liver-on-a-chip model to evaluate the temporal pharmacokinetic/pharmacodynamic relationship for terfenadine. Using the data obtained from the device, a mathematical model was developed to predict the effect of terfenadine in preclinical studies (McAleer et al., 2019). Similarly, a microscale cell culture analogue, composed of three cell culture chambers connected with fluidic channels to mimic multi-organ interactions, was used to test the toxicity of an anticancer drug, 5-fluorouracil. Similar to in vivo situations, each cell type exhibited differential responses and the responses in the microfluidic environment were different from those in static environments (Sung et al., 2010).

Organ-on-a-chip microfluidic devices and bioreactors are tightly linked to mathematical and computational modelling approaches fundamental for their design, optimisation and readout. Computational analysis is gaining increasing importance to interpret cell behaviour in in vitro system at single cell resolution and to understand patterns emerging from highly complex systems such as organ-on-a-chip emulation devices (Del Sol and Jung, 2021). In addition to data interpretation, computational modelling is increasingly used to simulate complex biological processes. For example, recent studies managed to satisfactorily model 3D chondrocyte cell culture growth in a porous scaffold placed in a bioreactor. The simulation predicted in good agreement with experimental evidence the 
local shear stresses, glucose concentration and 3D cell growth inside the porous scaffold (Shakhawath Hossain et al., 2015). Modelling has also been successfully applied to optimise experimental designs. For example, in a recent work, computational simulations were used to optimise the geometry and oxygen gradients inside hydrogels used to emulate vascularised bone (Bersini et al., 2016).

\section{Conclusions}

The maintenance and regeneration of human dental tissues constitute a great, unmet clinical need. Several attempts have already been made at using dental pulp and periodontal stem cells for regenerative purposes, mostly conducted on animal models (mice, rats, sheep etc.) or on simple cell culture systems. Despite some encouraging progresses, dental regenerative therapies are very far from any real clinical application. This is tightly connected with the absence of proper platforms that model human dental pulp in all its complexity and this lack of information and tools is a fundamental reason for the absence of credible pharmacological or cellular therapies for dental diseases. Innovative bioreactor-based and microfluidic organ-on-a-chip culture systems are providing increasingly more faithful tools to emulate human dental tissues. As such, these tools will have a great impact on issues concerning dental public health and design of new, dental-specific drugs. They will also represent a unique tool to assess the side effects that systemic treatments could exert on dental tissues, an often-neglected aspect that nevertheless represents an important burden for global healthcare systems. Thus, these approaches have the potential to advance the dental field, while promoting innovation and reducing dental health-care costs.

\section{Acknowledgments}

This work was financially supported by the University of Zurich and by the Swiss National Science Foundation (310030_197782).

The authors declare no competing interests.

\section{References}

Abaci HE, Shuler ML (2015) Human-on-a-chip design strategies and principles for physiologically based pharmacokinetics/pharmacodynamics modeling. Integr Biol (Camb) 7: 383-391.

Achyuta AK, Conway AJ, Crouse RB, Bannister EC, Lee RN, Katnik CP, Behensky AA, Cuevas J, Sundaram SS (2013) A modular approach to create a neurovascular unit-on-a-chip. Lab Chip 13: 542-553.

Adell R, Eriksson B, Lekholm U, Branemark PI, Jemt T (1990) Long-term follow-up study of osseointegrated implants in the treatment of totally edentulous jaws. Int J Oral Maxillofac Implants 5: 347-359.

Adriani G, Ma D, Pavesi A, Kamm RD, Goh EL (2017) A 3D neurovascular microfluidic model consisting of neurons, astrocytes and cerebral endothelial cells as a blood-brain barrier. Lab Chip 17: 448-459.

Atac B, Wagner I, Horland R, Lauster R, Marx U, Tonevitsky AG, Azar RP, Lindner G (2013) Skin and hair on-a-chip: in vitro skin models versus ex vivo tissue maintenance with dynamic perfusion. Lab Chip 13: 3555-3561.

Baudoin R, Griscom L, Monge M, Legallais C, Leclerc E (2007) Development of a renal microchip for in vitro distal tubule models. Biotechnol Prog 23: 1245-1253.

Benam KH, Villenave R, Lucchesi C, Varone A, Hubeau C, Lee HH, Alves SE, Salmon M, Ferrante TC, Weaver JC, Bahinski A, Hamilton GA, Ingber DE (2016) Small airway-on-a-chip enables analysis of human lung inflammation and drug responses in vitro. Nat Methods 13: 151-157.

Berahim Z, Moharamzadeh K, Rawlinson A, Jowett AK (2011) Biologic interaction of three-dimensional periodontal fibroblast spheroids with collagen-based and synthetic membranes. J Periodontol 82: 790-797.

Bersini S, Gilardi M, Arrigoni C, Talò G, Zamai M, Zagra L, Caiolfa V, Moretti M (2016) Human in vitro 3D co-culture model to engineer vascularized bonemimicking tissues combining computational tools and statistical experimental approach. Biomaterials 76: 157-172.

Bhatia SN, Ingber DE (2014) Microfluidic organson-chips. Nat Biotechnol 32: 760-772.

Callan DP (2007) Dental implant design and oral and systemic health. Compend Contin Educ Dent 28: 482-484, 486-490, 492.

Caton J, Bostanci N, Remboutsika E, De Bari C, Mitsiadis TA (2011) Future dentistry: cell therapy meets tooth and periodontal repair and regeneration. J Cell Mol Med 15: 1054-1065.

Chen H, Fu H, Wu X, Duan Y, Zhang S, Hu H, Liao Y, Wang T, Yang Y, Chen G, Li Z, Tian W (2020) Regeneration of pulpo-dentinal-like complex by a group of unique multipotent CD24a(+) stem cells. Sci Adv 6: eaay1514. DOI: 10.1126/sciadv.aay1514.

Del Sol A, Jung S (2021) The importance of computational modeling in stem cell research. Trends Biotechnol 39: 126-136.

Diekwisch TG (2001) The developmental biology of cementum. Int J Dev Biol 45: 695-706.

Douville NJ, Tung YC, Li R, Wang JD, El-Sayed ME, Takayama S (2010) Fabrication of two-layered channel system with embedded electrodes to measure resistance across epithelial and endothelial barriers. Anal Chem 82: 2505-2511.

Duffy DC, McDonald JC, Schueller OJ, Whitesides GM (1998) Rapid prototyping of microfluidic systems in poly(dimethylsiloxane). Anal Chem 70: 4974-4984.

Esposito M, Worthington HV (2013) Interventions for replacing missing teeth: hyperbaric oxygen 
therapy for irradiated patients who require dental implants. Cochrane Database Syst Rev 2013: CD003603. DOI: 10.1002/14651858.CD003603.pub3.

Franca CM, Tahayeri A, Rodrigues NS, Ferdosian S, Puppin Rontani RM, Sereda G, Ferracane JL, Bertassoni LE (2020) The tooth on-a-chip: a microphysiologic model system mimicking the biologic interface of the tooth with biomaterials. Lab Chip 20: 405-413.

Fron Chabouis H, Smail Faugeron V, Attal JP (2013) Clinical efficacy of composite versus ceramic inlays and onlays: a systematic review. Dent Mater 29: 1209-1218.

Gault P, Black A, Romette JL, Fuente F, Schroeder K, Thillou F, Brune T, Berdal A, Wurtz T (2010) Tissueengineered ligament: implant constructs for tooth replacement. J Clin Periodontol 37: 750-758.

Goldberg M, Kulkarni AB, Young M, Boskey A (2011) Dentin: structure, composition and mineralization. Front Biosci (Elite Ed) 3: 711-735.

Griep LM, Wolbers F, de Wagenaar B, ter Braak PM, Weksler BB, Romero IA, Couraud PO, Vermes I, van der Meer AD, van den Berg A (2013) BBB on chip: microfluidic platform to mechanically and biochemically modulate blood-brain barrier function. Biomed Microdevices 15: 145-150.

Gronthos S, Mankani M, Brahim J, Robey PG, Shi S (2000) Postnatal human dental pulp stem cells (DPSCs) in vitro and in vivo. Proc Natl Acad Sci U S A 97: 13625-13630.

Grosberg A, Alford PW, McCain ML, Parker KK (2011) Ensembles of engineered cardiac tissues for physiological and pharmacological study: heart on a chip. Lab Chip 11: 4165-4173.

Grosberg A, Nesmith AP, Goss JA, Brigham MD, McCain ML, Parker KK (2012) Muscle on a chip: in vitro contractility assays for smooth and striated muscle. J Pharmacol Toxicol Methods 65: 126-135.

Guerrero YA, Desai D, Sullivan C, Kindt E, Spilker ME, Maurer TS, Solomon DE, Bartlett DW (2020) A microfluidic perfusion platform for in vitro analysis of drug pharmacokinetic-pharmacodynamic (PK-PD) relationships. AAPS J 22: 53. DOI: 10.1208/s12248-0200430-y.

Hammond TG, Hammond JM (2001) Optimized suspension culture: the rotating-wall vessel. Am J Physiol Renal Physiol 281: F12-25.

Han M-J, Seo Y-K, Yoon H-H, Song K-Y, Park J-K (2010) Upregulation of bone-like extracellular matrix expression in human dental pulp stem cells by mechanical strain. Biotechnol Bioprocess Eng 15: 572-579.

Hata M, Naruse K, Ozawa S, Kobayashi Y, Nakamura N, Kojima N, Omi M, Katanosaka Y, Nishikawa T, Naruse K, Tanaka Y, Matsubara T (2013) Mechanical stretch increases the proliferation while inhibiting the osteogenic differentiation in dental pulp stem cells. Tissue Eng Part A 19: 625-633.

Howard PS, Kucich U, Taliwal R, Korostoff JM (1998) Mechanical forces alter extracellular matrix synthesis by human periodontal ligament fibroblasts. J Periodontal Res 33: 500-508.

Huh D, Leslie DC, Matthews BD, Fraser JP, Jurek S, Hamilton GA, Thorneloe KS, McAlexander MA, Ingber DE (2012) A human disease model of drug toxicity-induced pulmonary edema in a lung-on-achip microdevice. Sci Transl Med 4: 159ra147. DOI: 10.1126/scitranslmed.3004249.

Huh D, Matthews BD, Mammoto A, MontoyaZavala M, Hsin HY, Ingber DE (2010) Reconstituting organ-level lung functions on a chip. Science 328: 1662-1668.

Ji J, Sun W, Wang W, Munyombwe T, Yang XB (2014) The effect of mechanical loading on osteogenesis of human dental pulp stromal cells in a novel in vitro model. Cell Tissue Res 358: 123-133.

Kang KJ, Ju SM, Jang YJ, Kim J (2016) Indirect co-culture of stem cells from human exfoliated deciduous teeth and oral cells in a microfluidic platform. Tissue Eng Regen Med 13: 428-436.

Kim HJ, Ingber DE (2013) Gut-on-a-Chip microenvironment induces human intestinal cells to undergo villus differentiation. Integr Biol (Camb) 5: 1130-1140.

Kim HJ, Lee J, Choi JH, Bahinski A, Ingber DE (2016a) Co-culture of living microbiome with microengineered human intestinal villi in a gut-ona-chip microfluidic device. J Vis Exp: 54344. DOI: 10.3791/54344.

Kim HJ, Li H, Collins JJ, Ingber DE (2016b) Contributions of microbiome and mechanical deformation to intestinal bacterial overgrowth and inflammation in a human gut-on-a-chip. Proc Natl Acad Sci U S A 113: E7-15.

Kollar EJ (1986) Tissue interactions in development of teeth and related ectodermal derivatives. Dev Biol (N Y 1985) 4: 297-313.

Kraft DC, Bindslev DA, Melsen B, Abdallah BM, Kassem M, Klein-Nulend J (2010) Mechanosensitivity of dental pulp stem cells is related to their osteogenic maturity. Eur J Oral Sci 118: 29-38.

LaneSW, Williams DA, WattFM(2014) Modulating the stem cell niche for tissue regeneration. Nat Biotechnol 32: 795-803.

Li P, Zhang Y, Wang YM, Duan CM, Hao T, Wu BL, Wang CY (2012a) RCCS enhances EOE cell proliferation and their differentiation into ameloblasts. Mol Biol Rep 39: 309-317.

Li XJ, Valadez AV, ZuoP, NieZ(2012b) Microfluidic 3D cell culture: potential application for tissue-based bioassays. Bioanalysis 4: 1509-1525.

Maoz BM, Herland A, FitzGerald EA, Grevesse T, Vidoudez C, Pacheco AR, Sheehy SP, Park TE, Dauth S, Mannix R, Budnik N, Shores K, Cho A, Nawroth JC, Segrè D, Budnik B, Ingber DE, Parker KK (2018) A linked organ-on-chip model of the human neurovascular unit reveals the metabolic coupling of endothelial and neuronal cells. Nat Biotechnol 36: 865-874. 
Maschmeyer I, Lorenz AK, Schimek K, Hasenberg T, Ramme AP, Hubner J, Lindner M, Drewell C, Bauer S, Thomas A, Sambo NS, Sonntag F, Lauster R, Marx U (2015) A four-organ-chip for interconnected longterm co-culture of human intestine, liver, skin and kidney equivalents. Lab Chip 15: 2688-2699.

Mathes SH, Wohlwend L, Uebersax L, von Mentlen R, Thoma DS, Jung RE, Görlach C, GrafHausner U (2010) A bioreactor test system to mimic the biological and mechanical environment of oral soft tissues and to evaluate substitutes for connective tissue grafts. Biotechnol Bioeng 107: 1029-1039.

McAleer CW, Pointon A, Long CJ, Brighton RL, Wilkin BD, Bridges LR, Narasimhan Sriram N, Fabre K, McDougall R, Muse VP, Mettetal JT, Srivastava A, Williams D, Schnepper MT, Roles JL, Shuler ML, Hickman JJ, Ewart L (2019) On the potential of in vitro organ-chip models to define temporal pharmacokinetic-pharmacodynamic relationships. Sci Rep 9: 9619. DOI: 10.1038/s41598-019-45656-4.

Mitsiadis TA, Graf D (2009) Cell fate determination during tooth development and regeneration. Birth Defects Res C Embryo Today 87: 199-211.

Mitsiadis TA, Orsini G, Jimenez-Rojo L (2015) Stem cell-based approaches in dentistry. Eur Cell Mater 30: 248-257.

Miyashita S, Ahmed NE, Murakami M, Iohara K, Yamamoto T, Horibe H, Kurita K, Takano-Yamamoto T, Nakashima M (2017) Mechanical forces induce odontoblastic differentiation of mesenchymal stem cells on three-dimensional biomimetic scaffolds. J Tissue Eng Regen Med 11: 434-446.

Mohs RC, Greig NH (2017) Drug discovery and development: role of basic biological research. Alzheimers Dement (N Y) 3: 651-657.

Nanci A (2013) Ten Cate's Oral Histology. Development, structure, and function. Elsevier, St. Louis, Missouri, USA.

Natsiou D, Granchi Z, Mitsiadis TA, JimenezRojo L (2017) Generation of spheres from dental epithelial stem cells. Front Physiol 8: 7. DOI: 10.3389/ fphys.2017.00007.

Nikolaev M, Mitrofanova O, Broguiere N, Geraldo S, Dutta D, Tabata Y, Elci B, Brandenberg N, Kolotuev I, Gjorevski N, Clevers H, Lutolf MP (2020) Homeostatic mini-intestines through scaffold-guided organoid morphogenesis. Nature 585: 574-578.

Orsini G, Pagella P, Mitsiadis TA (2018a) Modern trends in dental medicine: an update for internists. Am J Med 131: 1425-1430.

Orsini G, Pagella P, Putignano A, Mitsiadis TA (2018b) Novel biological and technological platforms for dental clinical use. Front Physiol 9: 1102. DOI: 10.3389/fphys.2018.01102.

Pagella P, Caton J, Meisel CT, Mitsiadis TA (2020a) Ameloblastomas exhibit stem cell potential, possess neurotrophic properties, and establish connections with trigeminal neurons. Cells 9: 644. DOI: 10.3390/ cells9030644.

Pagella P, de Vargas Roditi L, Stadlinger B, Moor AE, Mitsiadis TA (2021) A single-cell atlas of human teeth. iScience 24 102405. DOI: 10.1016/j. isci.2021.102405.

Pagella P, Jimenez-Rojo L, Mitsiadis TA (2014a) Roles of innervation in developing and regenerating orofacial tissues. Cell Mol Life Sci 71: 2241-2251.

Pagella P, Miran S, Neto E, Martin I, Lamghari M, Mitsiadis TA (2020b) Human dental pulp stem cells exhibit enhanced properties in comparison to human bone marrow stem cells on neurites outgrowth. FASEB J 34: 5499-5511.

Pagella P, Neto E, Jimenez-Rojo L, Lamghari M, Mitsiadis TA (2014b) Microfluidics co-culture systems for studying tooth innervation. Front Physiol 5: 326. DOI: $10.3389 /$ fphys.2014.00326.

Pagella P, Neto E, Lamghari M, Mitsiadis TA (2015) Investigation of orofacial stem cell niches and their innervation through microfluidic devices. Eur Cell Mater 29: 213-223.

Pagella P, Porcheri C, Mitsiadis TA (2020c) Exploiting teeth as a model to study basic features of signaling pathways. Biochem Soc Trans 48: 2729-2742.

Pampaloni F, Reynaud EG, Stelzer EH (2007) The third dimension bridges the gap between cell culture and live tissue. Nat Rev Mol Cell Biol 8: 839-845.

Papapanou PN (1996) Periodontal diseases: epidemiology. Ann Periodontol 1: 1-36.

Park HS, Liu S, McDonald J, Thakor N, Yang IH (2013) Neuromuscular junction in a microfluidic device. Conf Proc IEEE Eng Med Biol Soc 2013: 28332835.

Park SH, Sim WY, Min BH, Yang SS, Khademhosseini A, Kaplan DL (2012) Chip-based comparison of the osteogenesis of human bone marrow- and adipose tissue-derived mesenchymal stem cells under mechanical stimulation. PLoS One 7: e46689. DOI: 10.1371/journal.pone.0046689.

Polini A, Prodanov L, Bhise NS, Manoharan V, Dokmeci MR, Khademhosseini A (2014) Organs-ona-chip: a new tool for drug discovery. Expert Opin Drug Discov 9: 335-352.

Prantil-Baun R, Novak R, Das D, Somayaji MR, Przekwas A, Ingber DE (2018) Physiologically based pharmacokinetic and pharmacodynamic analysis enabled by microfluidically linked organs-on-chips. Annu Rev Pharmacol Toxicol 58: 37-64.

Reinwald Y, El Haj AJ (2018) Hydrostatic pressure in combination with topographical cues affects the fate of bone marrow-derived human mesenchymal stem cells for bone tissue regeneration. J Biomed Mater Res A 106: 629-640.

Reza AT, Nicoll SB (2008) Hydrostatic pressure differentially regulates outer and inner annulus fibrosus cell matrix production in 3D scaffolds. Ann Biomed Eng 36: 204-213.

Roguljic H, Matthews BG, Yang W, Cvija H, Mina M, Kalajzic I (2013) In vivo identification of periodontal progenitor cells. J Dent Res 92: 709-715.

Salehipour Masooleh H, Ghavami-Lahiji M, Ciancio A, Tayebi L (2020) Microfluidic technologies using oral factors: saliva-based studies. In: Applications of Biomedical Engineering in Dentistry. 
Editor: Tayebi L. Springer International Publishing. pp: 339-358.

Shakhawath Hossain M, Bergstrom DJ, Chen XB (2015) A mathematical model and computational framework for three-dimensional chondrocyte cell growth in a porous tissue scaffold placed inside a bi-directional flow perfusion bioreactor. Biotechnol Bioeng 112: 2601-2610.

Shi M, Majumdar D, Gao Y, Brewer BM, Goodwin CR, McLean JA, Li D, Webb DJ (2013) Glia co-culture with neurons in microfluidic platforms promotes the formation and stabilization of synaptic contacts. Lab Chip 13: 3008-3021.

Shin M, Matsuda K, Ishii O, Terai H, KaazempurMofrad M, Borenstein J, Detmar M, Vacanti JP (2004) Endothelialized networks with a vascular geometry in microfabricated poly(dimethyl siloxane). Biomed Microdevices 6: 269-278.

Sivaraman A, Leach JK, Townsend S, Iida T, Hogan BJ, Stolz DB, Fry R, Samson LD, Tannenbaum SR, Griffith LG (2005) A microscale in vitro physiological model of the liver: predictive screens for drug metabolism and enzyme induction. Curr Drug Metab 6: 569-591.

Skardal A, Shupe T, Atala A (2016) Organoid-on-achip and body-on-a-chip systems for drug screening and disease modeling. Drug Discov Today 21: 13991411.

Smith AJ, Cassidy N, Perry H, Begue-Kirn C, Ruch JV, Lesot H (1995) Reactionary dentinogenesis. Int J Dev Biol 39: 273-280.

Smith Q, Gerecht S (2014) Going with the flow: microfluidic platforms in vascular tissue engineering. Curr Opin Chem Eng 3: 42-50.

Stevens A, Zuliani T, Olejnik C, LeRoy H, Obriot H, Kerr-Conte J, Formstecher P, Bailliez Y, Polakowska RR (2008) Human dental pulp stem cells differentiate into neural crest-derived melanocytes and have label-retaining and sphere-forming abilities. Stem Cells Dev 17: 1175-1184.

Sung JH, Kam C, Shuler ML (2010) A microfluidic device for a pharmacokinetic-pharmacodynamic (PKPD) model on a chip. Lab Chip 10: 446-455.

Tabatabaei FS, Jazayeri M, Ghahari P, Haghighipour N (2014) Effects of equiaxial strain on the differentiation of dental pulp stem cells without using biochemical reagents. Mol Cell Biomech 11: 209-220.

Torisawa YS, Spina CS, Mammoto T, Mammoto A, Weaver JC, Tat T, Collins JJ, Ingber DE (2014) Bone marrow-on-a-chip replicates hematopoietic niche physiology in vitro. Nat Methods 11: 663-669.

Wendt D, Riboldi SA, Cioffi M, Martin I (2009) Bioreactors in tissue engineering: scientific challenges and clinical perspectives. Adv Biochem Eng Biotechnol 112: 1-27.

Wenger KH, El-Awady AR, Messer RL, Sharawy MM, White G, Lapp CA (2011) Pneumatic pressure bioreactor for cyclic hydrostatic stress application: mechanobiology effects on periodontal ligament cells. J Appl Physiol (1985) 111: 1072-1079.
Woloszyk A, Holsten Dircksen S, Bostanci N, Muller R, Hofmann S, Mitsiadis TA (2014) Influence of the mechanical environment on the engineering of mineralised tissues using human dental pulp stem cells and silk fibroin scaffolds. PLoS One 9: e111010. DOI: 10.1371/journal.pone.0111010.

$\mathrm{Xu} X Y$, Li X, Wang J, He XT, Sun $\mathrm{HH}$, Chen FM (2019) Concise review: periodontal tissue regeneration using stem cells: strategies and translational considerations. Stem Cells Transl Med 8: 392-403.

Xuan K, Li B, Guo H, Sun W, Kou X, He X, Zhang Y, Sun J, Liu A, Liao L, Liu S, Liu W, Hu C, Shi S, Jin Y (2018) Deciduous autologous tooth stem cells regenerate dental pulp after implantation into injured teeth. Sci Transl Med 10: eaaf3227. DOI: 10.1126/ scitranslmed.aaf3227.

Yin X, Mead BE, Safaee H, Langer R, Karp JM, Levy O (2016) Engineering stem cell organoids. Cell Stem Cell 18: 25-38.

Yu V, Damek-Poprawa M, Nicoll SB, Akintoye SO (2009) Dynamic hydrostatic pressure promotes differentiation of human dental pulp stem cells. Biochem Biophys Res Commun 386: 661-665.

\section{Discussion with Reviewers}

Thomas Diekwisch: Which bioreactor approach will be most suitable for modelling the integrity of dental stem cells and potential epithelial-mesenchymal interactions? Do you think any of the models proposed will benefit dental tissue engineering?

Authors: Epithelial-mesenchymal interactions that lie at the basis of tooth development are very well modelled in classical organotypic cultures, which allow direct contact between the dental epithelium and mesenchyme. Tooth development happens in the absence of mastication-induced high mechanical loads and, therefore, bioreactors that apply significant forces would constitute an unnecessary input for the emulation of epithelial-mesenchymal interactions. Concerning the emulation of "isolated" dental pulp or periodontium, organ-on-a-chip devices represent the most promising design, as they allow for the integration of key elements, such as innervation, vascularisation and immune system, that are necessary to reconstitute a fully functional tissue. Concerning the formation/engineering of enamel, its biological (re)generation seems still far-fetched. This is a highly complex process realised over many years in vivo and even minor alterations to any of its aspects can lead to the generation of a defective enamel. Therefore, accelerating this process in vitro and obtaining a bona-fide enamel seems at the moment still unplausible.

Reviewer 2: Do the authors think that 3D cultures in spheroids or organoids will help the research in this specific field? 
Authors: 3D culture systems are already being applied to model dental tissues (Natsiou et al., 2017) and they will be of great benefit for the field. 3D culture systems provide a much more physiologically relevant geometry to the culture systems and can be implemented within organ-on-a-chip devices. We were recently awarded a research grant for the development of a "tooth-on-a-chip" system, which will include 3D culture elements.

Editor's note: The Scientific Editor responsible for this paper was Juerg Gasser. 